\author{
Joanna Stanisławiak-Rudowicz ${ }^{1}$, Anita Chudecka-Głaz ${ }^{2}$, Małgorzata Jazel ${ }^{3}$, Radosław Mądry ${ }^{4}$ \\ ${ }^{1}$ University Hospital of Lord's Transfiguration, Department of Gynecological Oncology, Poznan, Poland \\ ${ }^{2}$ Department and Clinic of Gynaecological Surgery and Gynaecological Oncology of Adults and Adolescents, Pomeranian Medical University \\ in Szczecin, Poland \\ ${ }^{3}$ AstraZeneca Pharma Poland Sp. z o.o. \\ ${ }^{4}$ Poznan University of Medical Sciences, Poland, University Hospital of Lord's Transfiguration, Department of Gynecological Oncology, Poznan, Poland
}

\title{
Desensitization in patients hypersensitive to platinum compounds in gynecologic oncology
}

\author{
Address for correspondence: \\ Dr n. med. Joanna Stanisławiak-Rudowicz \\ University Hospital of Lord's \\ Transfiguration, Department \\ of Gynecological Oncology, Poznan, Poland \\ e-mail: stanisl@interia.pl
}

Oncology in Clinical Practice

DOI: 10.5603/OCP.2021.0037

Copyright $(C) 2021$ Via Medica

ISSN 2450-1654

e-ISSN 2450-6478

\begin{abstract}
The treatment of ovarian cancer based on platinum analogs has taken on a new and additional importance in recent years. The introduction of modern maintenance therapy — PARP inhibitors — has significantly prolonged the time to progression in recurrent and newly diagnosed ovarian cancer and clinically meaningful, as per SOLO-2 results, prolonging overall survival in recurrent disease. This is an absolute breakthrough in the treatment of advanced forms of this cancer. Sensitivity to platinum is a prerequisite for the efficacy of this therapy as well as patient eligibility for treatment. Hypersensitivity issues can significantly limit access to this modern and effective maintenance therapy. Platinum hypersensitivity usually occurs in subsequent lines of therapy and with subsequent cycles of treatment. Hypersensitivity reactions cannot always be predicted, despite known risk factors. In order to maintain platinum-based treatment, we can modify premedication modalities, but appropriate desensitization protocols seem to be most effective. This article describes the most commonly used desensitization methods in patients with ovarian cancer and platinum hypersensitivity in a practical way, e.g., as they are used in the centers where the authors of this publication practice. Key words: ovarian cancer, platinum, carboplatin hypersensitivity, desensitization, PARP inhibitors
\end{abstract}

Oncol Clin Pract 2021; 17, 6: 263-270

\section{Introduction}

The change that has occurred in the treatment of ovarian cancer in recent years is related to the introduction of PARP inhibitors into its treatment. These drugs used as maintenance treatment after first-line response and after relapse significantly prolonged the time to progression [1-4], and in the case of olaparib as maintenance treatment after relapse, clinically meaningful prolonged lifetime [5].

The use of PARP inhibitors as maintenance treatment requires a response to treatment with platinum derivatives. Maintaining platinum treatment is particularly important because of that. The fairly common phenomenon of hypersensitivity to platinum often results in abandon- ing treatment with these cytostatic agents. This can be prevented by desensitization procedures, which allows the continuation of therapy and, in some ovarian cancer patients, the inclusion of maintenance treatment with PARP inhibitors.

\section{Hypersensitivity to platinum compounds - incidence and risk factors}

Drug hypersensitivity reactions (DHRs) include all drug reactions that clinically resemble allergic reactions. They are difficult to predict, vary in severity, and can be life-threatening to the patient, thus requiring

Received: 30.08.2021 Accepted: 30.08.2021 Early publication date: 30.12.2021

This article is available in open access under Creative Common Attribution-Non-Commercial-No Derivatives 4.0 International (CC BY-NC-ND 4.0) license, allowing to download articles and share them with others as long as they credit the authors and the publisher, but without permission to change them in any way or use them commercially. 
a change in therapy. It is estimated that DHRs account for $15 \%$ of all adverse drug reactions (ADRs) and affect approximately $7 \%$ of the general population [6]. Hypersensitivity reactions are mostly caused by common drugs (antibiotics and non-steroidal anti-inflammatory drugs), but they can be caused by any drug [7].

Most commonly, among anticancer drugs, sensitization reactions are caused mainly by platinum compounds (cisplatin, carboplatin, oxaliplatin), taxanes (paclitaxel, docetaxel), L-asparaginase, epipodophyllotoxins (teniposide, etoposide), monoclonal antibodies, procarbazine, and to a lesser extent, 6-mercaptopurine [7-11].

Carboplatin is estimated to cause approximately $0.73 \%$ of all reactions induced by intravenous chemotherapeutics and $50 \%$ of reactions induced by platinum compounds [12]. Hypersenitivity reactions are found in $1-44 \%$ of patients treated with carboplatin and in $5-20 \%$ of those treated with cisplatin [13]. The incidence of hypersensitivity reactions to platinum compounds administered in gynecologic oncology has been no higher than in the treatment of other cancers [14]. Their incidence is also not dependent on the route of administration $[15,16]$, but occurs more frequently with combination therapy, especially in therapy that is the gold standard for ovarian cancer treatment [17].

The CALYPSO trial found that hypersensitivity reactions were more common in those receiving carboplatin with paclitaxel than in those receiving carboplatin with doxorubicin $(18.8 \%$ vs. $5.6 \%)$ [18, 19]. Another study also showed higher incidence of hypersensitivity reactions during carboplatin monotherapy than during therapy with pegylated liposomal doxorubicin plus carboplatin (30\% vs. 0\%) [17].

A characteristic feature of hypersensitivity reactions to platinum compounds is that they occur only after administering several therapy cycles (usually after 8 cycles in the case of carboplatin), indicating the importance of the overall amount of the drug that has been administered. Reactions to carboplatin occur in less than $1 \%$ of those receiving $1-5$ cycles, in $6.5 \%$ receiving 6 cycles, in $27 \%$ receiving 7 or more cycles, and in nearly $44 \%$ receiving third-line therapy [20-24]. Similar observations were also made during cisplatin therapy. Half of the hypersensitivity reactions are of moderate to severe severity [21].

Risk factors for hypersensitivity reactions to platinum compounds include:

— age of less than 70 years [19];

- female sex [13];

- allergy to environmental factors or medications $[25,26]$;

- severe atopic disease [27];

- mastocytosis [27];

- chronic respiratory and cardiovascular diseases $[27,28]$;

- taking $\beta$-adrenergic blockers and angiotensin-converting enzyme inhibitors $[27,28]$;
- receiving a single dose of carboplatin of more than $650 \mathrm{mg}$ [24] or a total dose greater than $8000 \mathrm{mg}$ [29]; - length of drug interruption (varying according to different authors: more than 12 months [30], 13 months [24], or 2 years [26]). Schwartz et al. found, for example, that the risk of a severe hypersensitivity reaction during carboplatin administration was $47 \%$ when the time elapsed between the last administration of the drug in the first line of treatment and the first in the second line was more than 24 months, and $6.5 \%$ when it was less than 12 months [30].

The outcomes of studies evaluating the effect $B R C A 1 / 2$ gene mutation presence on hypersensitivity reactions to platinum compounds are conflicting (Tab. 1 [29, 31-33]).

\section{Mechanisms of hypersensitivity reactions to platinum compounds}

Both immune and non-immune mechanisms may underlie hypersensitivity reactions to drugs, including platinum compounds. The underlying factor in drug allergy is recognition of drugs or their metabolites by antibodies or activated $\mathrm{T}$ lymphocytes.

The second group includes, for example, reactions caused by non-immune mast cell and basophil degranulation or complement activation by drug [6].

Currently the most widely used hypersensitivity reaction classification is based on the time of symptoms onset as a main criteria. According to the classification, drug hypersensitivity reactions are divided into immediate and non-immediate reactions [6, 34-36] (Tab. 2).

CTCAE (Common Terminology Criteria for Adverse Events), ver 5.0 [37] criteria are used to assess the severity of hypersensitivity reactions (Tab. 3).

About half of the hypersensitivity reactions to platinum compounds are of moderate to severe severity, i.e., grade 2 to 3 according to the CTCAE. In a study by Garcia et al. involving a group of 62 patients receiving chemotherapy with platinum compounds, there were 11 grade 1 reactions (all in patients with mutations in

Table 1. Frequency of hypersensitivity reactions to platinum compounds among patients with and without BRCA1/2 gene mutations

\begin{tabular}{lcc}
\hline Study & $\begin{array}{c}\text { Patients with } \\
\text { BRCA1/2 mutation } \\
(\%) \mathbf{n}\end{array}$ & $\begin{array}{c}\text { Patients without } \\
\text { the mutation } \\
(\%) \mathbf{~}\end{array}$ \\
\hline Moon et al. [29] & $(79.3 \%) 29$ & $(50 \%) 58$ \\
\hline Altwerger et al. [30] & $(77.5 \%) 40$ & $(39.2 \%) 51$ \\
\hline Garcia et al. [28] & $(30.8 \%) 13$ & $(44.9 \%) 49$ \\
\hline Jerzak et al. [31] & $(5.4 \%) 37$ & $(11 \%) 84$ \\
\hline
\end{tabular}


Table 2. Types of drugs hypersensitivity reactions $[6,33-35]$

\begin{tabular}{|c|c|c|c|}
\hline $\begin{array}{l}\text { Type of } \\
\text { reaction }\end{array}$ & Time of occurrence & Resistance & Symptoms \\
\hline Immediate & $\begin{array}{l}\text { Within } 1-6 \text { hours of drug } \\
\text { administration. } \\
\text { The faster a reaction develops, } \\
\text { the more severe the } \\
\text { symptoms }\end{array}$ & $\begin{array}{l}\text { In the case of the allergic } \\
\text { mechanism, they are } \\
\text { triggered by the presence } \\
\text { of specific IgE (type I } \\
\text { according to Gell and } \\
\text { Coombs), formed upon } \\
\text { repeated exposure to } \\
\text { a given drug }\end{array}$ & $\begin{array}{l}\text { In } 90 \% \text { of patients: skin and mucosal symptoms (urticaria, } \\
\text { angioedema, conjunctivitis, rhinitis). } \\
\text { In } 40 \% \text { of patients: bronchospasm. } \\
\text { In } 30-35 \% \text { of patients: defense of blood pressure. } \\
\text { Gastrointestinal symptoms (nausea, vomiting, diarrhea, } \\
\text { abdominal pain) are also developed. The most serious } \\
\text { symptom is anaphylactic shock: cardiovascular failure } \\
\text { that can lead to death. Mild reactions usually resolve with } \\
\text { administration of antihistamines and corticosteroids }\end{array}$ \\
\hline $\begin{array}{l}\text { Not } \\
\text { immediate }\end{array}$ & $\begin{array}{l}\text { More than an hour after the } \\
\text { drug was administered }\end{array}$ & $\begin{array}{l}\text { Allergic reactions } \\
\text { are mediated by } \mathrm{T} \\
\text { lymphocytes }\end{array}$ & $\begin{array}{l}\text { A variety of skin manifestations are most commonly } \\
\text { found, such as maculopapular rashes, delayed urticaria, } \\
\text { and persistent erythema. Organ manifestations such as } \\
\text { hepatitis, renal failure, interstitial lung disease, anemia, } \\
\text { neutropenia, and thrombocytopenia may also occur }\end{array}$ \\
\hline
\end{tabular}

Table 3. Classification of the severity of hypersensitivity reactions according to CTCAE

\begin{tabular}{ll}
\hline Grade & Symptoms \\
\hline 1 & Mild and transient; it is not necessary to discontinue the drug or institute additional therapy \\
\hline $\begin{array}{l}\text { Moderate intensity; the medication should be discontinued, but symptomatic treatment (e.g., antihistamines and } \\
\text { corticosteroids) results in rapid improvement (administered no longer than } 24 \text { hours) }\end{array}$ \\
\hline $\begin{array}{l}\text { Significant intensity, but not immediately life-threatening; symptoms do not resolve quickly enough after symptomatic } \\
\text { treatment or discontinuation of therapy or occur after temporary improvement. Hospitalization is recommended }\end{array}$ \\
\hline 5 & Life-threatening. Immediate intervention is recommended \\
\hline
\end{tabular}

$B R C A 1$ or $B R C A 2$ genes), 14 grade 2 reactions, and 16 grade 3 reactions (all in patients without mutations in $B R C A 1$ or BRCA2 genes) [29]. No grade 4 or 5 reactions were reported in this study, but fatal cases have been reported in the literature [38, 39].

\section{Prevention of hypersensitivity reactions to platinum compounds}

Before administering platinum compounds, an analysis of the patient's risk of hypersensitivity reactions should be performed, taking into account the factors mentioned earlier. Special caution is recommended for patients who are receiving the $8^{\text {th }}$ cycle of carboplatin or the $2^{\text {nd }}$ cycle for treatment of relapse.

Premedication with antihistamines and corticosteroids is not sufficient to prevent IgE-dependent hypersensitivity reactions, and therefore it is not recommended for standard administration before platinum compounds [40-42]. Some authors suggest including such treatment in patients who have already received 8 cycles of treatment but have not yet experienced a hypersensitivity reaction. One study also found that slower administration of carboplatin with premedication (3 hours instead of the standard half an hour) significantly reduced the rate of hypersensitivity reactions from $21 \%$ to $3.4 \%$ [43].

When a hypersensitivity reaction occurs, it is crucial to recognize it as soon as possible and implement appropriate management.

It is necessary to have a procedure in place for dealing with hypersensitivity reactions and the equipment necessary for resuscitation before administering platinum compounds. Patients should also be advised of the possibility of adverse reactions, and that they should notify medical personnel as soon as possible if they notice them [28].

\section{Management in case of allergic reaction}

In case of allergic reaction, anti-allergic medications (steroids, antihistamines) should be given and a slower infusion of the cytostatic should be used (prolonged from 30 minutes to 3 hours). In this situation, it is sometimes possible to complete the entire scheduled dose of cytostatic agent, but it is important to remember that despite the use of additional drugs in premedication, there is still a high risk of sensitization. There 
have been reports in the literature [13] that if a patient receives 8 carboplatin infusions without complications, premedication should be increased before the administering the next course in order to reduce the risk of an allergic reaction.

\section{Management of allergic reactions to platinum compounds}

If allergic reactions to carboplatin occur, one possible treatment modification is substitution with cisplatin. Cross-reactivity between cytostatic agents has not been proven, so in case of hypersensitivity to one of the platinum analogues, their replacement - carboplatin with cisplatin or cisplatin with carboplatin - should always be considered [11, 44].

A second possible scenario is to attempt to desensitize the patient (desensitization). A carboplatin desensitization procedure should be used if there is a high risk of anaphylaxis. Carboplatin administration in a desensitization procedure does not affect response according to RECIST criteria [45].

In the situation of planned desensitization to carboplatin, an appropriate procedure should be sought and then tailored to the circumstances of the given unit.

Contraindications to desensitization include [46]:

- patient fear and lack of consent;

- late sensitization reactions after carboplatin (more than 24 hours);

- erythema multiforme;

- Stevens-Johnson syndrome;

One option for premedication in a desensitization protocol is the administration of an oral steroid (dexamethasone) for several days prior to the protocol [21].

More than a dozen different carboplatin desensitization procedures have been described in the literature, with patient numbers ranging from 3 to 63 . Different desensitization options, divided into 4 to 12 stages, were used in the presented procedures. Steroids, antihistamines, and $\mathrm{H} 2$ blockers were suggested for each procedure. Drug administration in desensitization was started from a few days before cytostatic administration to a few hours earlier and continued for a few days afterwards. The duration of cytostatic drug administration varied from 2 hours to 2 days [13].

It is important to note that desensitization procedures are time-consuming, but a greater treatment tolerance has been noted when cytostatic agents are administered at lower levels and for longer periods of time.

Making the decision to administer a cytostatic in a desensitization procedure always involves assessing the benefits and risks of the drug and informing the patient of all the consequences of the desensitization procedure, including the risk of anaphylaxis and even death. The patient should give informed written consent for foregoing the procedure.

Based on the literature presented at the Department of Gynecologic Oncology at the University Hospital of Lord's Transfiguration in Poznań, a desensitization protocol (Tab. 4) has been developed and is used in patients with grade 3 and 4 allergic reaction (according to the CTCAE v5.0) induced by carboplatin and cisplatin, for which platinum is an option according to the ESMO-ESGO 2019 guidelines [47].

\section{Desensitization procedure — proceedings}

The patient is hospitalized for approximately 3-4 days depending on the desensitization regimen being used. Before hospital admission, oral low-dose steroids (methylprednisolone at $4 \mathrm{mg}$, prednisone at $5 \mathrm{mg}$, dexamethasone at $4 \mathrm{mg}$ once daily) are considered for several days, as well as antihistamines (clemastine, loratadine).

When a patient qualifies for chemotherapy, the desensitization procedure is preceded by obtaining informed written consent. On the day before carboplatin administration, intravenous steroids (in our case, dexamethasone at $8 \mathrm{mg}$ ) and antihistamines and $\mathrm{H} 2$ blockers are administered by oral or intravenous route.

When prescribing chemotherapy in a carboplatin desensitization protocol, the total dose of carboplatin is first calculated, usually 5-6 AUC. After calculating the total dose, the total is divided into four parts that will correspond to 4 bottles of carboplatin at increasing concentrations. Bottle 1 contains the cytostatic agent at a concentration of $0.1 \%$ of the calculated dose, bottle 2 contains $1 \%$, bottle 3 contains $10 \%$, and bottle 4 contains the remaining $88.9 \%$ of the calculated dose of carboplatin, respectively.

For example, with a calculated carboplatin dose of $700 \mathrm{mg}$, a prescription with the following doses is sent to the cytostatic laboratory:

- Bottle 1 - $0.7 \mathrm{mg}$ carboplatin;

- Bottle 2 - $7 \mathrm{mg}$ carboplatin;

- Bottle 3 - $70 \mathrm{mg}$ carboplatin;

- Bottle 4-622.3 mg carboplatin.

On the day of scheduled chemotherapy, premedication begins in the morning and the following agents are administered:

— intravenous steroid;

- antihistamines such as loratadine, clemastine orally;

- and also $\mathrm{H} 2$ blockers in this case orally.

Administration of the first medication dose begins approximately 30 minutes after premedication.

\section{Requirements for medical staff}

1. The resuscitation team or ICU should be notified of a planned desensitization protocol with a high risk of anaphylaxis before a carboplatin infusion is 
Table 4. Desensitization protocol used at the Department of Gynecological Oncology of University Hospital of Lord's Transfiguration in Poznań

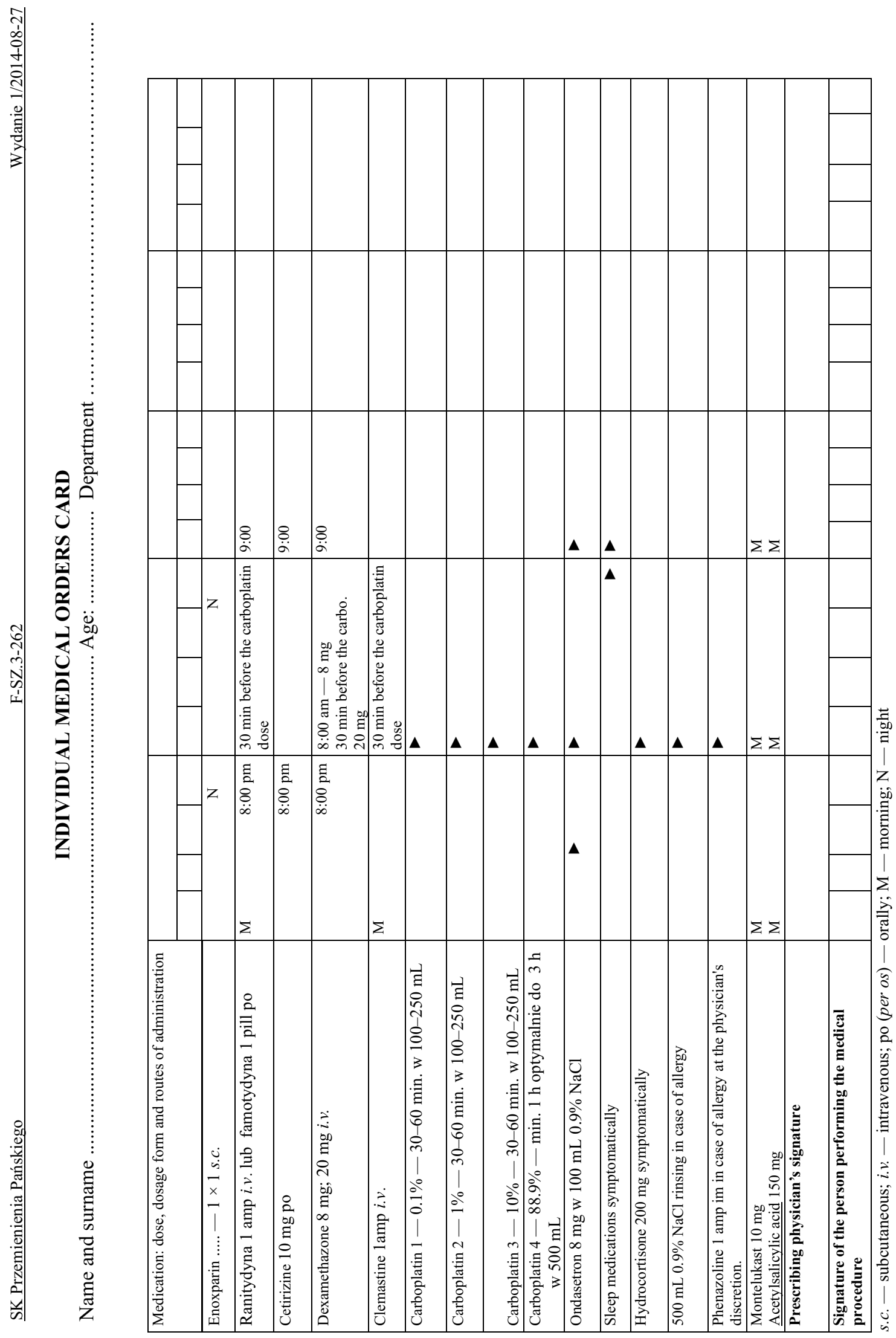


Table 5. Effectiveness of using the desensitization procedure

\begin{tabular}{lccc}
\hline Study & $\begin{array}{c}\text { Patients/ovarian } \\
\text { cancer } \mathbf{n}^{*}\end{array}$ & $\begin{array}{c}\text { Number of } \\
\text { protocols used } \mathbf{n} * *\end{array}$ & $\begin{array}{c}\text { Procedures without } \\
\text { any complications } \% \\
\text { (n) }\end{array}$ \\
\hline Lee et al. 2005 [45] & $57 / 42$ & 255 & $\begin{array}{c}\text { Deaths during the } \\
\text { procedure } \mathbf{n}\end{array}$ \\
\hline Castellas et al. 2008 [50] & $98 / 65$ & 413 & $67(225)$ \\
\hline Altweregr et al. 2017 [32] & $129 / 109$ & 788 & $96(753)$ \\
\hline
\end{tabular}

*most patients were treated with platinum compounds; **depending on the number of stages (from 5 to 13 ) in a given protocol

started. The resuscitation team should be prepared to provide rapid assistance as needed.

2. One nurse should be assigned to the patient for whom the desensitization protocol is planned.

3. The physician should be present for the connection and initial infusion of chemotherapy; he/she should remain in constant contact with the nurse and patient, ready to respond immediately (known as direct single-person supervision).

4. Both the physician and the nurse should be trained to recognize early signs of an allergic reaction (e.g., the patient's involuntary scratching of the neck) to initiate anti-allergic treatment early enough.

The patient should be advised on the potential for hypersensitivity reactions each time before starting an infusion, during the desensitization procedure and the need to notify medical personnel immediately if alarming symptoms occur. This is important because $96 \%$ of the sensitization reactions observed during a desensitization protocol are skin symptoms [46]. For safety reasons and to ensure proper patient care during the desensitization protocol, it is not advisable to run two protocols at the same time on the unit.

The first three doses of the cytostatic should be dissolved in $100-250 \mathrm{~mL}$ of solution. The volume depends on the logistical ability of the nursing staff to administer the medication at the scheduled time. According to the experience from our unit, it is often not possible to set the pump to a volume of $100 \mathrm{~mL}$, moreover it is difficult to transfuse $100 \mathrm{~mL}$ in $60 \mathrm{~min}$ utes. After several desensitization procedures, if there are no contraindications to more intravenous fluids, the first three concentrations are given in a volume of $250 \mathrm{~mL}$ over $30 \mathrm{~min}$, max. $60 \mathrm{~min}$. The rate of cytostatic agent administration is usually increased every 15 minutes at each of the carboplatin concentrations. The last of the concentrations $(88.9 \%$ of the total dose) is dissolved in a volume of $500 \mathrm{~mL}$ with an administration time of 60-180 minutes, with a recommended increase in the rate of drug administration at 15 and 30 minutes of infusion. Premedication in the form of steroids, anti-allergic drugs, and $\mathrm{H} 2$ blockers is continued on the day the cytostatic infusion ends and on the following day.
There are reports in the literature of possible causes of some allergic reactions to carboplatin (redness, hot flushes). These may be related to vasodilation resulting from the sudden release of mediators such as prostaglandins and leukotrienes. To reduce the risk of mast cell activation, some centers recommend administering acetylsalicylic acid at $325 \mathrm{mg}$ orally and montelukast at $10 \mathrm{mg}$ orally once daily. These drugs are recommended from the next course in the desensitization protocol, when any sensitization reaction has occurred with the previous administration. Medications are given for 2 days earlier and on the day of cytostatic agent administration [48].

If a sensitization reaction occurs during administration of a cytostatic at the three lowest concentrations, administration of subsequent concentrations is not recommended, as it is associated with a high risk of a serious sensitization reaction. Likewise, if a grade 3 or 4 allergy (according to CTCAE v5.0) occurs at any level of desensitization.

In situations where grade 1 or 2 sensitization occurs during the administration of the last bottle of chemotherapy (highest concentration) and symptoms resolve rapidly after administration of anti-allergic medications, the administration of the remainder of the cytostatic agent may be considered, taking into account the benefits and risks of continuation, and guided by the patient's attitude and concerns.

In patients who develop symptoms of severe hypersensitivity to the drug, discontinuation is often necessary, and reintroduction of the drug is associated with a risk of developing anaphylactic shock and death [11]. The exact mechanism of action in desensitization is unknown, but it is thought that the process hyposensitizes mast cells and inhibits both their immediate and delayed activation [49].

\section{Effectiveness of desensitization protocols}

The effectiveness of desensitization protocols, e.g., for platinum compounds, has been evaluated in several studies as shown in Table 5. In all the cited studies, either no hypersensitivity reaction or less severe hypersensitivity reactions, compared to the original reaction, were observed when desensitization protocols were used. 


\section{Conclusions}

Hypersensitivity to platinum compounds is a serious clinical problem, not only because of the possibility of causing anaphylactic shock and death of the patient. Platinum compounds are the primary medications used to treat some cancers, including ovarian cancer. If such a treatment is discontinued due to hypersensitivity, the patient's chances of survival are greatly diminished. The exclusion of platinum compounds from treatment also closes off the possibility of using PARP inhibitors in maintenance therapy that significantly extend disease-free time and overall survival.

\section{Acknowledgments}

Editorial assistance for the development of this manuscript was provided by Proper Medical Writing Sp. z o. o., with the financial support of AstraZeneca Pharma Poland Sp. z o. o.

\section{Disclosure of potential conflicts of interest}

R. M has acted as a consultant and speaker for AstraZeneca and GSK and has served as a Board member for AstraZeneca, GSK is an investigator on PARPi trials with olaparib, niraparib.

A. Ch-G has acted as a consultant and speaker for AstraZeneca and GSK and has served as a Board member for AstraZeneca, is an investigator on PARPi trials with olaparib, niraparib.

J. S-R has acted as a speaker for AstraZeneca

\section{References}

1. Moore K, Colombo N, Scambia G, et al. Maintenance Olaparib in Patients with Newly Diagnosed Advanced Ovarian Cancer. N Engl J Med. 2018; 379(26): 2495-2505, doi: 10.1056/NEJMoa1810858, indexed in Pubmed: 30345884.

2. Pujade-Lauraine E, Ledermann JA, Selle F, et al. Olaparib tablets as maintenance therapy in patients with platinum-sensitive, relapsed ovarian cancer and a BRCA1/2 mutation (SOLO2/ENGOT-Ov21): a double-blind, randomised, placebo-controlled, phase 3 trial. Lancet Oncol. 2017: 18(9): 1274-1284.

3. González-Martín A, Pothuri B, Vergote I, et al. PRIMA/ENGOT-OV26/GOG-3012 Investigators. Niraparib in Patients with Newly Diagnosed Advanced Ovarian Cancer. N Engl J Med. 2019; 381(25): 2391-2402, doi: 10.1056/NEJMoa1910962, indexed in Pubmed 31562799

4. Mirza MR, Monk BJ, Herrstedt J, et al. ENGOT-OV16/NOVA Investigators. Niraparib Maintenance Therapy in Platinum-Sensitive, Recurrent Ovarian Cancer. N Engl J Med. 2016; 375(22): 2154-2164, doi: 10.1056/NEJMoa1611310, indexed in Pubmed: 27717299.

5. Poveda A, Floquet A, Ledermann J, et al. Olaparib tablets as maintenance therapy in patients with platinum-sensitive relapsed ovarian cancer and a BRCA1/2 mutation (SOLO2/ENGOT-Ov21): a final analysis of a double-blind, randomised, placebo-controlled, phase 3 trial. Lancet Oncol. 2021; 22(5): 620-631, doi: 10.1016/s1470-2045(21)00073-5.

6. Demoly P, Adkinson NF, Brockow K, et al. International Consensus on drug allergy. Allergy. 2014; 69(4): 420-437, doi: 10.1111/all.12350, indexed in Pubmed: 24697291.
7. Demoly P, Bousquet J. Drug allergy diagnosis work up. Allergy. 2002; 57 Suppl 72: 37-40, doi: 10.1034/j.1398-9995.57.s72.7.x, indexed in Pubmed: 12144553

8. Lipp HP, Hartmann JT, Hartmann JT, et al. Toxicity of platinum compounds. Expert Opin Pharmacother. 2003; 4(6): 889-901, doi: 10.1517/14656566.4.6.889, indexed in Pubmed: 12783586.

9. Shepherd GM. Hypersensitivity reactions to chemotherapeutic drugs. Clin Rev Allergy Immunol. 2003; 24(3): 253-262, doi: 10.1385/CRIAl:24:3:253, indexed in Pubmed: 12721396

10. Chung $\mathrm{CH}$. Managing premedications and the risk for reactions to infusional monoclonal antibody therapy. Oncologist. 2008; 13(6): 725-732, doi: 10.1634/theoncologist.2008-0012, indexed in Pubmed: 18586928.

11. Boulanger J, Boursiquot JN, Cournoyer G, et al. Comité de l'évolution des pratiques en oncologie. Management of hypersensitivity to platinum- and taxane-based chemotherapy: cepo review and clinical recommendations. Curr Oncol. 2014; 21(4): e630-e641, doi: 10.3747/co.21.1966, indexed in Pubmed: 25089112.

12. Demoor $P A$, Matusov $Y$, Kelly $C$, et al. A retrospective review of the frequency and nature of acute hypersensitivity reactions at a medium-sized infusion center: comparison to reported values and inconsistencies found in literature. J Cancer. 2011; 2: 153-164, doi: 10.7150/jca.2.153, indexed in Pubmed: 21475720

13. Makrilia N, Syrigou E, Kaklamanos I, et al. Hypersensitivity reactions associated with platinum antineoplastic agents: a systematic review. Met Based Drugs. 2010; 2010, do: 10.1155/2010/207084, indexed in Pubmed: 20886011.

14. Navo M, Kunthur A, Badell ML, et al. Evaluation of the incidence of carboplatin hypersensitivity reactions in cancer patients. Gynecol Oncol. 2006; 103(2): 608-613, doi: 10.1016/j.ygyno.2006.04.002, indexed in Pubmed: 16797060.

15. Shukunami K, Kurokawa T, Kawakami Y, et al. Hypersensitivity reactions to intraperitoneal administration of carboplatin in ovarian cancer: the first report of a case. Gynecol Oncol. 1999; 72(3): 431-432, doi: 10.1006/gyno.1998.5273, indexed in Pubmed: 10053120.

16. Gobel BH. Chemotherapy-induced hypersensitivity reactions. Oncol Nurs Forum. 2005; 32(5): 1027-1035, doi: 10.1188/05.onf.1027-1035, indexed in Pubmed: 16136200

17. Markman M, Moon J, Wilczynski S, et al. Single agent carboplatin versus carboplatin plus pegylated liposomal doxorubicin in recurrent ovarian cancer: final survival results of a SWOG (S0200) phase 3 randomized trial. Gynecol Oncol. 2010; 116(3): 323-325, doi: 10.1016/j.ygyno.2009.11.026, indexed in Pubmed: 20044128.

18. Pujade-Lauraine E, Wagner $U$, Aavall-LundqvistE, et al. Pegylated liposomal Doxorubicin and Carboplatin compared with Paclitaxel and Carboplatin for patients with platinum-sensitive ovarian cancer in late relapse. J Clin Oncol. 2010; 28(20): 3323-3329, doi: 10.1200/JCO.2009.25.7519, indexed in Pubmed: 20498395

19. Joly F, Ray-Coquard I, Fabbro M, et al. Decreased hypersensitivity reactions with carboplatin-pegylated liposomal doxorubicin compared to carboplatin-paclitaxel combination: analysis from the GCIG CALYPSO relapsing ovarian cancer trial. Gynecol Oncol. 2011; 122(2): 226-232, doi: 10.1016/j. ygyno.2011.04.019, indexed in Pubmed: 21575983.

20. Kook H, Kim KM, Choi SH, et al. Life-threatening carboplatin hypersensitivity during conditioning for autologous PBSC transplantation: successful rechallenge after desensitization. Bone Marrow Transplant. 1998; 21(7): 727-729, doi: 10.1038/sj.bmt.1701161, indexed in Pubmed: 9578315.

21. Markman M, Kennedy A, Webster K, et al. Clinical features of hypersensitivity reactions to carboplatin. J Clin Oncol. 1999; 17(4): 1141, doi: 10.1200/JCO.1999.17.4.1141, indexed in Pubmed: 10561172.

22. Sliesoraitis S, Chikhale PJ. Carboplatin hypersensitivity. Int J Gynecol Cancer. 2005; 15(1): 13-18, doi: 10.1111/j.1048-891x.2005.14401.x, indexed in Pubmed: 15670291

23. Hoekstra AV, Hurteau JA, Kirschner CV, et al. The combination of monthly carboplatin and weekly paclitaxel is highly active for the treatment of recurrent ovarian cancer. Gynecol Oncol. 2009; 115(3): 377-381, doi: 10.1016/j. ygyno.2009.08.021, indexed in Pubmed: 19800107.

24. Sugimoto $H$, Iwamoto $T$, Murashima $Y$, et al. Risk factors contributing to the development of carboplatin-related delayed hypersensitivity reactions in Japanese patients with gynecologic cancers. Cancer Chemother Pharmacol. 2011; 67(2): 415-419, doi: 10.1007/s00280-010-1338-5, indexed in Pubmed: 20443001

25. Markman M, Zanotti K, Kulp B, et al. Relationship between a history of systemic allergic reactions and risk of subsequent carboplatin hypersensitivity. Gynecol Oncol. 2003; 89(3): 514-516, doi: 10.1016/s0090-8258(03)00155-0, indexed in Pubmed: 12798720.

26. Gadducci A, Tana R, Teti G, et al. Analysis of the pattern of hypersensitivity reactions in patients receiving carboplatin retreatment for recurrent ovarian cancer. Int J Gynecol Cancer. 2008; 18(4): 615-620, doi: 10.1111/j.1525-1438.2007.01063.x, indexed in Pubmed: 18754135.

27. Simons FE, Ardusso LRF, Bilò MB, et al. World Allergy Organization. World allergy organization guidelines for the assessment and mana- 
gement of anaphylaxis. World Allergy Organ J. 2011; 4(2): 13-37, doi: 10.1097NOX.0b013e318211496c, indexed in Pubmed: 23268454

28. Roselló S, Blasco I, Fabregat LG, et al. Corrections to "Management of infusion reactions to systemic anticancer therapy: ESMO Clinical Practice Guidelines". Ann Oncol. 2018; 29: iv260, doi: 10.1093/annonc/mdy158.

29. Garcia A, Frahm C, Jeter J, et al. Incidence of hypersensitivity reactions to carboplatin or paclitaxel in patients with ovarian, Fallopian tube, or primany peritoneal cancer with or without BRCA1 or BRCA2 mutations. J Clin Oncol . 2018; 36(15_suppl): e18758-e18758, doi: 10.1200/jco.2018.36.15_suppl. e18758.

30. Schwartz JR, Bandera C, Bradley A, et al. Does the platinum-free interval predict the incidence or severity of hypersensitivity reactions to carboplatin? The experience from Women and Infants' Hospital. Gynecol Oncol. 2007; 105(1) 81-83, doi: 10.1016/jygyno 2006 10.047 indexed in Pubmed: 17157366.

31. Moon DH, Lee JM, Noonan AM, et al. Deleterious BRCA1/2 mutation is an independent risk factor for carboplatin hypersensitivity reactions. $\mathrm{Br} \mathrm{J}$ Cancer. 2013; 109(4): 1072-1078, doi: 10.1038/bjc.2013.389, indexed in Pubmed: 23867999.

32. Altwerger G, Florsheim EB, Menderes G, et al. Impact of carboplatin hypersensitivity and desensitization on patients with recurrent ovarian cance. J Cancer Res Clin Oncol. 2018; 144(12): 2449-2456, doi: 10.1007/s00432018-2753-y, indexed in Pubmed: 30255380

33. Jerzak KJ, Deghan Manshadi S, Ng P, et al. Prevention of carboplatin-induced hypersensitivity reactions in women with ovarian cancer. J Oncol Pharm Pract. 2018; 24(2): 83-90, doi: 10.1177/1078155216679028, indexed in Pubmed: 27856924

34. Metcalfe DD, Peavy RD, Gilfillan AM, et al. Understanding the mechanisms of anaphylaxis. Curr Opin Allergy Clin Immunol. 2008; 8(4): 310-315, doi 10.1097/ACl.0b013e3283036a90, indexed in Pubmed: 18596587.

35. Gleich GJ, Leiferman KM. Anaphylaxis: implications of monoclonal antibody use in oncology. Oncology (Williston Park). 2009; 23(2 Suppl 1): 7-13, indexed in Pubmed: 19385161.

36. Vultaggio $A$, Castells $M C$. Hypersensitivity reactions to biologic agents. Immunol Allergy Clin North Am. 2014; 34(3): 615-32, ix, doi: 10.1016/j.iac.2014.04.008, indexed in Pubmed: 25017680

37. https://ctep.cancer.gov/protocoldevelopment/electronic applications/docs/CTCAE v5 Quick Reference 8.5x11 pdf (7.02.2020)

38. Zweizig S, Roman LD, Muderspach LI. Death from anaphylaxis to cisplatin: a case report. Gynecol Oncol. 1994; 53(1): 121-122, doi 10.1006/gyno.1994.1098, indexed in Pubmed: 8175010.

39. Dizon DS, Sabbatini PJ, Aghajanian C, et al. Analysis of patients with epithelia ovarian cancer or fallopian tube carcinoma retreated with cisplatin after the development of a carboplatin allergy. Gynecol Oncol. 2002; 84(3): 378-382 doi: 10.1006/gyno.2001.6519, indexed in Pubmed: 11855873.
40. Polyzos A, Tsavaris N, Kosmas $\mathrm{C}$, et al. Hypersensitivity reactions to carboplatin administration are common but not always severe: a 10-year experience. Oncology. 2001; 61(2): 129-133, doi: 10.1159/000055363, indexed in Pubmed: 11528251

41. Gammon D, Bhargava P, McCormick MJ, et al. Hypersensitivity and idiosyncratic reactions to oxaliplatin. Cancer. 2004; 100(1): 211-212, doi: 10.1002/cncr.11901, indexed in Pubmed: 14692042.

42. Syrigou E, Triantafyllou O, Makrilia N, et al. Acute hypersensitivity reactions to chemotherapy agents: an overview. Inflamm Allergy Drug Targets. 2010; 9(3): 206-213, doi: 10.2174/187152810792231887, indexed in Pubmed: 20632960.

43. O'Cearbhaill R, Zhou Q, lasonos A, et al. The prophylactic conversion to an extended infusion schedule and use of premedication to prevent hypersensitivity reactions in ovarian cancer patients during carboplatin retreatment. Gynecol Oncol. 2010; 116(3): 326-331, doi: 10.1016/j. ygyno.2009.10.070, indexed in Pubmed: 19944454.

44. Ottaiano A, Tambaro R, Greggi S, et al. Safety of cisplatin after severe hypersensitivity reactions to carboplatin in patients with recurrent ovarian carcinoma. Anticancer Research. 2003; 23(4): 3465-3468.

45. Lee CW, Matulonis UA, Castells MC. Rapid inpatient/outpatient desensitization for chemotherapy hypersensitivity: standard protocol effective in 57 patients for 255 courses. Gynecol Oncol. 2005; 99(2): 393-399, doi: 10.1016/j.ygyno.2005.06.028, indexed in Pubmed: 16054201.

46. Castells M. Drug Desensitization in Oncology: Chemotherapy Agents and Monoclonal Antibodies. In: Pichler WJ. ed. Drug hypersensitivity. Karger, Basel 2007: 404-413.

47. Colombo N, Sessa C, du Bois A, et al. ESMO-ESGO Ovarian Cancer Consensus Conference Working Group. ESMO-ESGO consensus conference recommendations on ovarian cancer: pathology and molecular biology, early and advanced stages, borderline tumours and recurrent diseaset. Ann Oncol. 2019; 30(5): 672-705, doi: 10.1093/annonc/mdz062, indexed in Pubmed: 31046081.

48. Breslow RG, Caiado J, Castells MC. Acetylsalicylic acid and montelukast block mast cell mediator-related symptoms during rapid desensitization. Ann Allergy Asthma Immunol. 2009; 102(2): 155-160, doi: 10.1016/S1081-1206(10)60247-5, indexed in Pubmed: 19230468.

49. Ang WX, Church AM, Kulis M, et al. Mast cell desensitization inhibits calcium flux and aberrantly remodels actin. J Clin Invest. 2016; 126(11): 4103-4118, doi: 10.1172/JCl87492, indexed in Pubmed: 27669462.

50. Castells MC, Tennant NM, Sloane DE, et al. Hypersensitivity reactions to chemotherapy: outcomes and safety of rapid desensitization in 413 cases. J Allergy Clin Immunol. 2008; 122(3): 574-580, doi: 10.1016/j. jaci.2008.02.044, indexed in Pubmed: 18502492. 